\title{
我国煤成烃气的 $\delta^{13} \mathrm{C}-\boldsymbol{R}_{0}$ 关系
}

\author{
戴金星戚厚发 \\ (北京石油勘探开发科学研究院)
}

关链词煤成烃气 $\delta^{13} \mathrm{C}-R_{0}$ 方程、碳同位素、气源对比

近十年来,我们在松辽、渤海湾、鄂尔多斯、四川、准噶尔、塔里木、楚雄、琼东南与东海 9 个 盆地及 14 个煤矿, 取了 202 个煤成气样, 获得甲烷及其同系物的碳同位素 $\left(\delta^{13} \mathrm{C}_{1} 、 \delta^{13} \mathrm{C}_{2} 、 \delta^{13} \mathrm{C}_{3}\right.$ 和 $\left.\delta^{13} \mathrm{C}_{4}\right)$ 分析数据 426 个, 从中选择出原生的煤成气, 并对其可确定源岩成熟度 $\left(R_{0}\right)$ 进行 了测定. 从这些资料, 明显可见我国原生煤成烃气的 $\delta^{13} \mathrm{C}$ 值随其源岩成熟度增加而增大的特 征.

\section{一、煤成气的 $\delta^{13} \mathbf{C}-R_{0}$ 特征}

1. 煤成气的 $\delta^{13} C_{1}-R_{0}$ 回归方程 1985 年, 我们测定 168 个原生煤成气 $\delta^{13} \mathrm{C}_{1}$ 值, 从中 选择出源岩成熟度较可靠的 32 个样品, 测定其源岩的 $R_{0}$ 值, 通过微机成图并回归出方程式. 这是我国首先提出最完善的 $\delta^{13} \mathrm{C}_{1}-R_{0}$ 关系图和回归方程 ${ }^{[1]}$ :

$$
\delta^{13} \mathrm{C}_{1} \approx 14.12 \log R_{0}-34.39,
$$

德国西北盆地煤成气 $\delta^{13} \mathrm{C}_{1}-R_{0}$ 回归方程式为 ${ }^{[2]}$

$$
\delta^{13} \mathrm{C}_{1} \approx 14 \log R_{0}-28 \text {. }
$$

Caypool 提出北美煤成气回归方程式为 ${ }^{[2]}$

$$
\delta^{13} \mathrm{C}_{\mathrm{b}} \approx 15 \log R_{\mathrm{o}}-35,
$$

式 (1)、(2)、（3）均具有 $\delta^{13} \mathrm{C}_{1}$ 值随 $R_{0}$ 值增加而增大的共同特点. 比较式 (1)、(2)、(3) 可 知, 我国煤成气 $\delta^{13} \mathrm{C}_{1}-R_{0}$ 回归方程与北美的相近, 但比德国西北盆地的轻约 $5 \%$.

2. 煤成气的 $\delta^{13} \mathbf{C}_{2}-\boldsymbol{R}_{0}$ 和 $\delta^{13} \mathbf{C}_{3}-\boldsymbol{R}_{0}$ 回归方程 近来, 我们综合研究了从 65 个煤成气 样获得的 141 个 $\delta^{13} \mathrm{C}_{2} 、 \delta^{13} \mathrm{C}_{3} 、 \delta^{13} \mathrm{C}_{4}$ 分析成果（其中 $\delta^{13} \mathrm{C}_{4}$ 仅 14 个, 故未深入研究 $\delta^{13} \mathrm{C}_{4}-R_{0}$ 关 系), 从中测定了较可靠的源岩成熟度值, 分别作出 $8^{13} \mathrm{C}_{2}-R_{0}$ 和 $\delta^{13} \mathrm{C}_{3}-R_{0}$ 关系图 (图 1) 及回 归出方程式,这项工作在我国也是首次进行. 获得回归方程是:

$$
\begin{aligned}
& \delta^{13} \mathrm{C}_{2} \approx 8.16 \log R_{0}-25.71, \\
& \delta^{13} \mathrm{C}_{3} \approx 7.12 \log R_{4}-24.03 .
\end{aligned}
$$

分析图 1 和公式 (1)、(4)、(5) 可知: 1) 甲烷碳同位素回归线和乙烧碳同位素回归线的 差值,比乙烷碳同位素回归线和丙烷碳同位素回归线的差值大得多. 在同一成熟度,前者是后 者的五倍多；2）甲烷碳同位素回归线和乙烧碳同位素回归线的差值，乙烷碳同位素回归线和 丙烷碳同位素回归线的差值，均具有随成熟度增大而减小的特征；3）原始资料点主要分布在 ${ }^{1{ }^{13}} \mathrm{C}_{1}$ 回归线两侧约 $2.0 \%, \delta^{13} \mathrm{C}_{2}$ 和 $\delta^{13} \mathrm{C}_{3}$ 回归线两侧约 $1.0 \%$ 范围内, 这是判别气源许可范围,

本文 1988 年 8 月 3 日收到. 


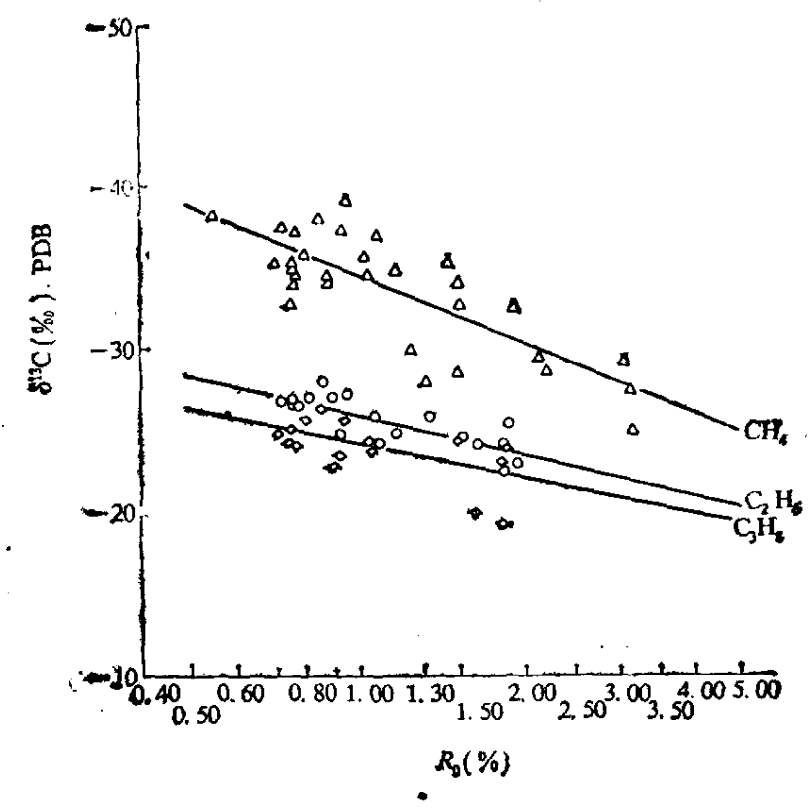

图 1 我国煤成烃气 $\delta^{13} \mathrm{C}-R_{0}$ 关系图

也就是说不仅落在回归线上点是煤成气，在许可数域内点群也是煤成气. 同样 $R_{0}$ 也有一个 .相应许可范围区间值.

\section{二、讨 论}

1. 应用 $\delta^{13} \mathrm{C}-R_{0}$ 关系图，可以进行有机热降解气的气源对比. 若知某天然气的 $\delta^{13} \mathrm{C}_{1}$ 、 $\delta^{13} \mathrm{C}_{2}$ 和 $\delta^{13} \mathrm{C}_{3}$ 值, 用图解法, 在纵坐标上分别取三个点, 从该三点起点作出与横坐标平行三条 线, 三平行线若与对应的 $\delta^{13} \mathrm{C}_{1} 、 \delta^{13} \mathrm{C}_{2}$ 和 $\delta^{13} \mathrm{C}_{3}$ 回归线相交, 则是煤成气; 若不相交或错位相交, 则不是煤成气. 例如: 鄂尔多斯盆地胜利井气田上任 6 井下石盒子 组 天然气的 $\delta^{13} \mathrm{C}_{1}$ 为 $-35.343 \% ; \delta^{13} \mathrm{C}_{2}$ 为 $-26.375 \% ; \delta^{13} \mathrm{C}_{3}$ 为 $-24.333 \%$ 在图 2 纵坐标上分别取 $-35.343 \%$ 点 $A,-26.375 \%$ 点 $B$ 和 $-24.333 \%$ 点 $C$, 作 $A 、 B 、 C$ 点与横坐标的平行线, 而与 $\delta^{13} \mathrm{C}_{1}$ 、 $\delta^{13} \mathrm{C}_{2}$ 和 $\delta^{13} \mathrm{C}_{3}$ 回归线 分别交于 $\mathrm{A}^{\prime} 、 \mathrm{~B}^{\prime}$ 和 $\mathrm{C}^{\prime}$ 点,由此判定任 6 井的天然气是煤成气, 这与 以其它依据研究确定其是煤成气的结论是一 致的 ${ }^{[1]}$. 鄂尔多斯盆地华池油田上华 11-32 井延长统天然气的 $\delta^{13} \mathrm{C}_{1}$ 为 $-46.414 \%, \delta^{13} \mathrm{C}_{2}$ 为 $-35.945 \%$ 和 $\delta^{13} \mathrm{C}_{3}$ 为 $-32.298 \%$, 在 图 2 纵坐标上分别取 $-46.414 \%$ 点 $\mathrm{D}$, $-35.945 \%$ 点 $\mathrm{E}$ 和 $-32.298 \%$ 点 $\mathrm{F}$, 分别作 $D 、 E 、 F$ 与横坐标的平行线, $D$ 平行线与 $\delta^{13} \mathrm{C}$, 回归线没有交点, $\mathrm{E}$ 和 $\mathrm{F}$ 的平行线同 $\delta^{13} \mathrm{C}_{2}$ 和 $\delta^{13} \mathrm{C}_{3}$ 回归线没有交点, 而和 $\delta^{13} \mathrm{C}_{1}$ 回归线错 位相交于 $E^{\prime}$ 和 $F^{\prime}$ 点, 故其不是煤成气。 因 华 11-32 井的天然气是华池油田的伴生气,

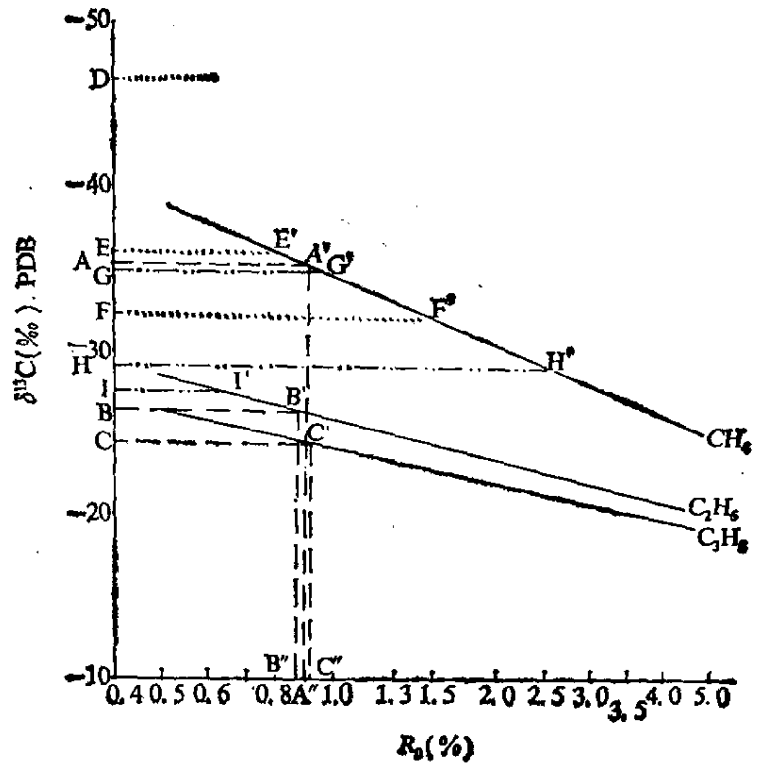

图 2 利用煤成烃气 $\delta^{3} \mathrm{C}-R_{0}$ 图进行气源 对比和判别成熟度 
故属油型气. 四川盆地中坝气田雷三气藏中 24 井天然气的 $\delta^{13} \mathrm{C}_{1}-34.96 \% 、 \delta^{13} \mathrm{C}_{2}-29.03 \%$ 、 $\delta^{13} C_{3}-27.84 \%$, 在图 2 纵坐标上分别取 $\delta^{13} C_{1}$ 值、 $\delta^{13} C_{2}$ 值和 $\delta^{13} C_{3}$ 值的 $G 、 H 、 I$ 点, 用上述相 同方法作出该三点横坐标平行线, $G$ 平行线与 $\delta^{13} \mathrm{C}_{1}$ 回归线交于 $\mathrm{G}^{\prime}$ 点, $\mathrm{H}$ 和 $\mathrm{I}$ 平行线则不与对 应的 $\delta^{13} \mathrm{C}_{2}$ 和 $\delta^{13} \mathrm{C}_{3}$ 回归线相交, 而与 $\delta^{13} \mathrm{C}_{1}$ 和 $\delta^{13} \mathrm{C}_{2}$ 回归线错位相交于 $\mathrm{H}^{\prime}$ 和 $\mathrm{I}^{\prime}$ 点, 由此确定雷三 气藏的天然气不是煤成气, 这与有关研究确定雷三气藏的天然气是油型气 ${ }^{[1]}$ 的结论是吻合的.

2. 利用 $\delta^{13} \mathrm{C}-R_{0}$ 图和回归方程确定煤成气成熟度. 已知煤成气的 $\delta^{13} \mathrm{C}_{1} 、 \delta^{13} \mathrm{C}_{2}$ 和 $\delta^{13} \mathrm{C}_{3}$ 值, 取图 2 纵坐标上该三值的三个点, 作此三点与横坐标三条平行线, 分别相交于 $\delta^{13} \mathrm{C}_{1} 、 \delta^{13} \mathrm{C}_{2}$ 和 $\delta^{13} \mathrm{C}_{3}$ 回归线于三点, 再从后三点作纵坐标平行线交于横坐标, 便可读取成熟度. 例如, 上述 任 6 井煤成气用此方法, 在横坐标上得 $\delta^{13} \mathrm{C}_{1}$ 的 $\mathrm{A}^{\prime \prime}$ 点 $R_{0}$ 为 $0.90 \%, \delta^{13} \mathrm{C}_{2}$ 的 $\mathrm{B}^{\prime \prime}$ 点 $R_{0}$ 为 $0.86 \%$, $\delta^{13} C_{3}$ 的 $\mathrm{C}^{\prime \prime}$ 点 $R_{0}$ 为 0.91 (图 2). 若以公式 (1)、(4)、(5) 来计算, 得 $\delta^{13} \mathrm{C}_{t}$ 的 $R_{0}$ 为 $0.86 \%$ ， $\delta^{13} \mathrm{C}_{2}$ 的 $R_{\mathrm{o}}$ 为 $0.83 \% ， \delta^{13} \mathrm{C}_{3}$ 的 $R_{\mathrm{0}}$ 为 $0.95 \%$ 。该井实测石炭二叠系源岩 $R_{\mathrm{o}}$ 为 $0.75-0.84 \%$. 由上可见, 计算法所得 $R_{\mathrm{o}}$ 低值与实测 $R_{0}$ 高值重叠一致, 图解法 $R_{0}$ 低值与实测 $R_{\mathrm{o}}$ 高值仅差 $0.02 \%$ 十分接近, 并在许可范围区间值内. 故所获三个结果基本吻合. 根据具体地质背景, 取 各种方法获得最低 $R_{0}$ 值的区间值作为该煤成气源岩成熟度是适宜的，由此可得，任 6 井煤成 气源岩综合成熟度为 $0.75-0.86 \%$, 这与实测 $R_{0}$ 为 $0.75-0.84 \%$ 十分接近. James 曾作过 相似于 $\delta^{13} \mathrm{C}-R_{\text {。 }}$ 图的 $\delta^{13} \mathrm{C}-\mathrm{LOM}$, 或 $\delta^{13} \mathrm{C}-\mathrm{TAI}$ 图 ${ }^{[3]}$, 但该图并未把油型气和煤成气分开. 实 际上在相同成熟度下, 煤成气的相应组分比油型气的对应组分的 $\delta^{13} \mathrm{C}$ 重 ${ }^{[4]}$, 这从图 2 中华 1132 井与中 24 井油型气 $\delta^{13} \mathrm{C}_{2}$ 值, $\delta^{13} \mathrm{C}_{3}$ 值错位相交于煤成气的 $\delta^{13} \mathrm{C}_{1}$ 和 $\delta^{13} \mathrm{C}_{2}$ 回归线便是一证. 因此, 应用煤成气的 $\delta^{13} \mathrm{C}-R_{0}$ 图来进行气源对比, 确定煤成气的成熟度,比利用 James 的 $\delta^{23} \mathrm{C}-$ LOM 图或 $\delta^{13} \mathrm{C}-\mathrm{TAI}$ 图的更准确.

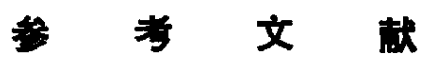

[1]武金星等,煤成气地质研究, 石油工业出版社, 1987，156-170.

[2] Schoell, M., AAPG, 67 -1983), 12: 2225-2238.

[3] James, A. T., AAPG, 67 (1983), 7: 1176-1191.

[4]臷金星等, 天然气地质学概论, 石油工业出版社(出版中). 